\title{
Circumscribed Storiform Collagenoma Associated with Rubinstein-Taybi Syndrome in a Young Adolescent
}

\author{
Nick Zavras ${ }^{a}$ Rosario Mennonna ${ }^{b}$ Spyros Maris $^{a} \quad$ George Vaos $^{a}$ \\ ${ }^{a}$ Department of Paediatric Surgery, Attikon University General Hospital, School of \\ Medicine, National and Kapodistrian University of Athens, Athens, and ${ }^{\mathrm{b}}$ Department of \\ Pathology, General Hospital of Nikaia 'Agios Panteleimon', Piraeus, Greece
}

\section{Key Words}

Rubinstein-Teybi syndrome $\cdot$ Circumscribed storiform collagenoma $\cdot$ Adolescent

\begin{abstract}
Rubinstein-Taybi syndrome is a rare congenital neurodevelopmental disorder characterized by dysmorphic features, skeletal abnormalities, growth deficiency, and mental retardation. Circumscribed storiform collagenoma is a distinct benign fibromatous tumor that presents either as solitary tumor or in association with other syndromes. In this report, we describe a 16-year-old male with Rubinstein-Taybi syndrome associated with circumscribed storiform collagenoma. To our knowledge, this association has not been previously described in the literature.

(C) 2016 The Author(s)

Published by S. Karger AG, Basel
\end{abstract}

\section{Introduction}

The term 'circumscribed storiform collagenoma' (CSC) was first introduced by Maize et al. [1] to describe an uncommon benign lesion of the skin, similar to sclerotic fibroma associated with Cowden syndrome [2]. Rubinstein-Taybi syndrome (RSTS) is a very rare condition that derives from mutations in the CREB-binding protein (CREBBP) on chromosome 16 p13.3 and the E1A-binding protein p300 (EP300) on chromosome 22 [3]. It is characterized by a broad spectrum of clinical features such as mental retardation, short stature, craniofacial and limb abnormalities, as well as skin disorders. Along with these abnormalities,

\section{KARGER}

Nick Zavras

Department of Paediatric Surgery, Attikon University General Hospital 1 Rimini street

Haidari, GR-12426 Athens (Greece)

E-Mailnzavras@med.uoa.gr 
Zavras et al.: Circumscribed Storiform Collagenoma Associated with Rubinstein-Taybi Syndrome in a Young Adolescent

ophthalmic lesions, congenital heart diseases, and renal abnormalities may also coexist [3]. Most boys have undescended testes [3], and a high susceptibility to the formation of keloids on the skin has been referred to [3].

In this report, we describe the extremely rare case of CSC associated with RSTS in a young adolescent.

\section{Case Report}

A 16-year-old boy with RSTS was evaluated in our department for a mass at the site of an old scar after surgery for left undescended testes performed at the age of 2 years. His past medical history disclosed surgery for transposition of the great vessels that was performed at the age of 2 months. Physical examination revealed a mentally retarded adolescent with a height of $135 \mathrm{~cm}$, microcephaly and beaked nose, low hanging septum, atypical smile, almost closed eyes, high arched palate, hirsutism, and enlarged first finger and hallux. A keloid was noticed at the site of the cardiac surgery (fig. 1). A huge multilobulated mass of pink color with crypts and fissures was noticed in the left groin (fig. 2). The lesion was asymptomatic and first appeared when the patient was 8 years old. It continued to steadily grow in size until the time of presentation. There was no referred pain on palpation, and the mass was totally excised under general anesthesia.

The surgical sample measured $8 \times 4 \times 3 \mathrm{~cm}$ and exhibited epidermal hyperplasia and hyperkeratosis with focal papillary configuration. Histopathology showed that the specimen was composed of bundles of collagen arranged in a storiform pattern mixed with fibroblasts (fig. 3a). The collagen bundles were separated by elongated clefts (fig. 3b). Although this type of lesion could match the description of a keloid, the intense plexoid configuration of the collagen bundles classified the lesion into the category of CSC.

\section{Discussion}

RSTS was first described in 1963 [4] and represents an extremely rare multiple congenital anomaly with an incidence ranging from 100,000 to 125,000 live births [3]. The syndrome may be observed in either sex. Although it develops sporadically, an autosomal dominant inheritance has been noted in some cases [5]. Up to the 90s, the investigation of the syndrome was based on clinical and radiological examination [5]. Hannekam et al. [6] proposed four clinical principles that support the diagnosis of RSTS: the beaked nose with low hanging septum, grimacing smile, broad thumb and large hallux, and mental retardation. The patient presented herein was also born with transposition of the great vessels and undescended testes. However, molecular studies in 1991 suggested that the lesion is a genetic anomaly derived from de novo genetic mutations in the chromosomal region 16p13.3 [3]. Further studies identified CREBBP gene mutation in 50\% of patients with RSTS [3] and EP300 gene mutation in $8 \%$ [3]. Currently, up to $70 \%$ of patients clinically recognized as RSTS cases may have their diagnosis confirmed by genetic analysis [3]. The diagnosis of RSTS in the present case was based on clinical characteristics since the patient fulfilled the clinical criteria of the syndrome [6]. Moreover, our patient was born with a congenital heart disease and undescended testes.

Cutaneous manifestations of RSTS are numerous: the most common include keloid development (either spontaneous or posttraumatic) and hirsutism [7]. Other less common anomalies are capillary hemangiomas, café-au-lait spots, seborrheic dermatitis, pilomatri- 


\section{Case Reports in Dermatology}

\begin{tabular}{l|l}
\hline Case Rep Dermatol 2016;8:59-63 \\
\hline DOI: 10.1159/000444630 & $\begin{array}{l}\text { ( ) 2016 The Author(s). Published by S. Karger AG, Basel } \\
\text { www.karger.com/cde }\end{array}$ \\
\hline
\end{tabular}

Zavras et al.: Circumscribed Storiform Collagenoma Associated with Rubinstein-Taybi Syndrome in a Young Adolescent

comas, abnormal dermatoglyphics, and follicular hyperkeratosis [7]. To our knowledge, this is the first reported case of CSC associated with RSTS.

CSC is an unusual benign tumor which occurs more often in young and middle-aged adults [8]. It can present either occasionally [8] or in association with other diseases and syndromes $[2,9,10]$. Although Cowden syndrome is the most common condition to be associated with multiple CSC, the lesion has also been identified in patients with LhermitteDuclos disease [9] and Bannayan-Ruvalcaba-Riley syndrome [10]. Lhermitte-Duclos disease, otherwise known as dysplastic cerebellar gangliocytoma, is a rare hamartomatous disease of the cerebellum that slowly enlarges within the cerebellar cortex [9]. Bannayan-RuvalcabaRiley syndrome is characterized by macrocephaly, cutaneous lipomas, developmental delay and intestinal polyps [10]. All these syndromes share certain common features: they are autosomal dominant disorders characterized by mutations in the PTEN tumor suppressor gene found on chromosome 10q [10].

Clinically, an isolated CSC is a small lump or nodule of whitish, pink, or skin color that is usually located on the face and limbs, but it can also develop on the chest, scalp, nail, and oral mucosa [11]. In a series of 11 patients, Rapini and Golitz [12] noted a small female predilection (8/11). The average lesion size was $5.5 \mathrm{~mm}$ with a range of 2-9 $\mathrm{mm}$. Histopathological examination of CSC is necessary to confirm diagnosis. Major findings include the presence of a distinctly confined tumor with atrophy of the epidermis, and sclerotic collagen bundles separated by clefts that may contain mucin or may be empty $[1,9]$.

A considerable number of skin tumors must be differentiated from CSC such as giant cell collagenoma, fibrolipoma, sclerotic lipoma, pleomorphic fibroma, dermatofibroma, and intradermal Spitz nevus [11]. Surgical excision in free margins is the treatment of choice [11]. However, some tumors may reoccur [13].

The association of CSC and RSTS could be a new entity. Although the presence of CSC in our case may be accidental, one could speculate that mutations in the CPB gene may be responsible for CSC. The CPB gene activates various transcription factors and is involved in several conditions such as inflammation in asthma, hematopoiesis, angiogenesis, myelodysplastic syndromes, and acute myeloid leukemia [14].

This is the first description of CSC associated with reported RSTS. Physicians must be aware when evaluating patients with RSTS to ascertain the prevalence of this association, while further studies are needed to support any genetic association.

\section{Statement of Ethics}

The parents have given written informed consent to publish this case.

\section{Disclosure Statement}

The authors declare that there are no conflicts of interest.

\section{References}

1 Maize J, Leidel G, Mullins VS, Metcalf JS: Circumscribed storiform collagenoma. Am J Dermatopathol 1989;11:287.

-2 Weary PE, Gorlin RJ, Gentry WC Jr, Comer SA, Greer KE: Multiple hamartoma syndrome (Cowden's disease). Arch Derm 1972;106:682-690. 
Zavras et al.: Circumscribed Storiform Collagenoma Associated with Rubinstein-Taybi Syndrome in a Young Adolescent

3 Milani D, Manzo FMP, Pezzani L, Ajmore P, Gervasini C, Menni F, Esposito S: Rubinstein-Taybi syndrome: clinical features, genetic basis, diagnosis and management. Ital J Pediatr 2015;41:4.

$\checkmark 4$ Rubinstein JH, Tayni H: Broad thumbs and toes and facial abnormalities. A possible mental retardation. Am J Dis Child 1963;105:688-608.

5 Marion RW, Garcia DM, Karasik JB: Apparent dominant transmission of the Rubinstein-Taybi syndrome. Am J Med Genet 1993;46:284-287.

6 Hannekam RCM, van de Boogard MJ, Spijker HG: Rubinstein-Taybi syndrome in The Netherlands. Am J Med Genet Suppl 1990;6:17-20.

7 Centeno PG, Rosón E, Peteri C, Pereiro M, Toribio J: Rubinstein-Taybi syndrome and ulerythema ophryogenes in a 9-year-old boy. Pediatr Dermatol 1999;16:134-136.

-8 Al-Darajii WI, Ramsay HM, Ali RBM: Storiform collagenoma as a clue for Cowden disease or PTEN hamartoma tumour syndrome. J Clin Pathol 2007;60:840-842.

-9 Chapman MS, Perry AE, Baugman RD: Cowden's syndrome, Lhermitte-Duclos disease, and sclerotic fibroma. Am J Dermatopathol 1998;20:413-416.

10 Zori RT, Marsh DJ, Graham GE, Marlish EB, Eng C: Germline PTEN mutation in a family with Cowden syndrome and Bannayan-Ruvalcaba-Riley syndrome. Am J Med Genet 1998;80:399-402.

11 Stocchero GF: Storiform collagenoma: case report. Einstein (Sau Paolo) 2015;13:103-105.

12 Rapini RP, Golitz LE: Sclerotic fibromas of the skin. J Am Acad Dermatol 1989;20:266-271.

13 Cohen PR, Tschen JA, Abaya-Blas R, Cochran RJ: Recurrent sclerotic fibroma of the skin. Am J Dermatopathol 2002;24:54-58.

14 Bayle P, Bazex J, Lamant L, Laique D, Durieu C, Albest B: Multiple perforating and non-perforating pilomatricomas in a patient with Churg-Strauss syndrome and Rubinstein-Taybi syndrome. J Eur Acad Dermatol Venereol 2004;18:607-610.

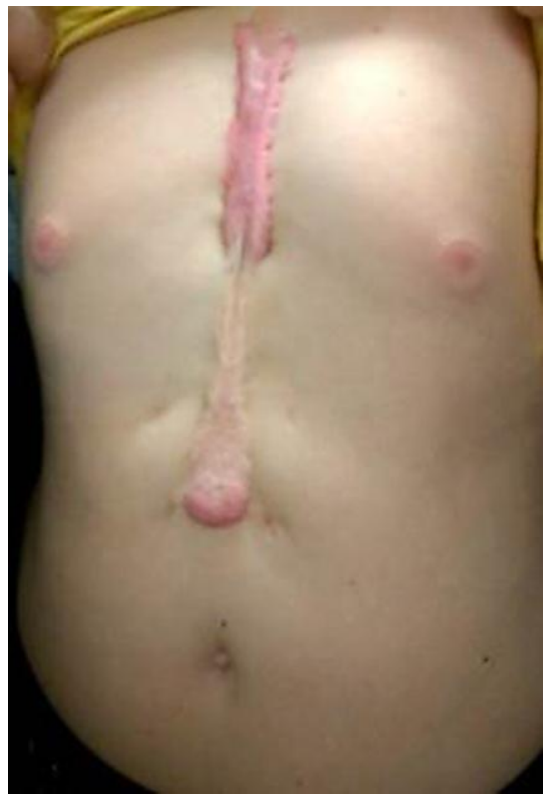

Fig. 1. A keloid along the location of the previous sternotomy for correction of transposition of the great arteries. 
Case Reports in
Dermatology

\begin{tabular}{l|l}
\hline Case Rep Dermatol 2016;8:59-63 \\
\hline DOI: $10.1159 / 000444630$ & $\begin{array}{l}\text { (c) 2016 The Author(s). Published by S. Karger AG, Basel } \\
\text { www.karger.com/cde }\end{array}$ \\
\hline
\end{tabular}

Zavras et al.: Circumscribed Storiform Collagenoma Associated with Rubinstein-Taybi Syndrome in a Young Adolescent

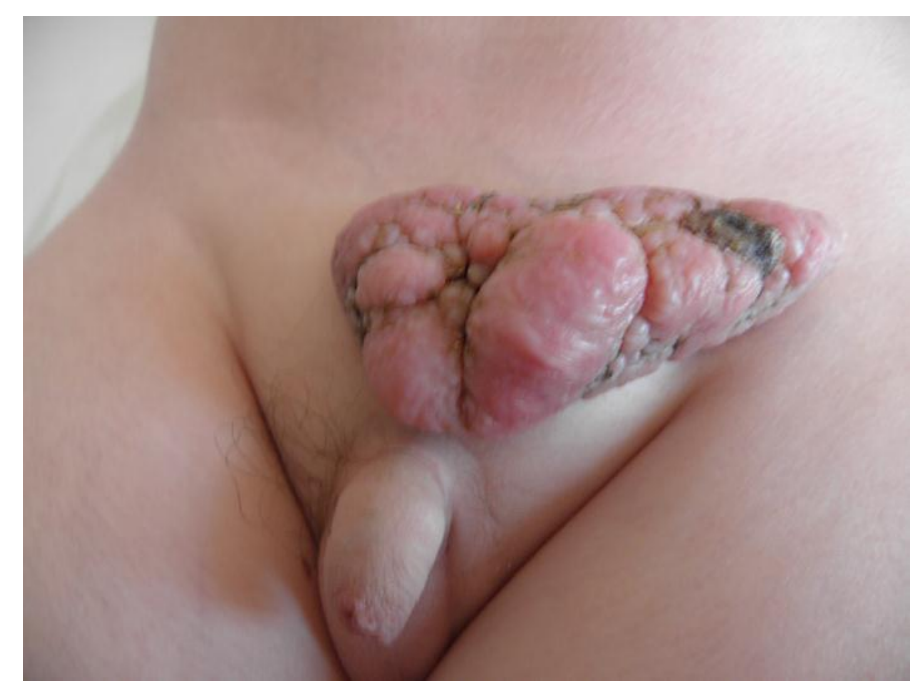

Fig. 2. A large multilobulated mass of pink color with crypts and fissures was noticed in the left inguinal site.

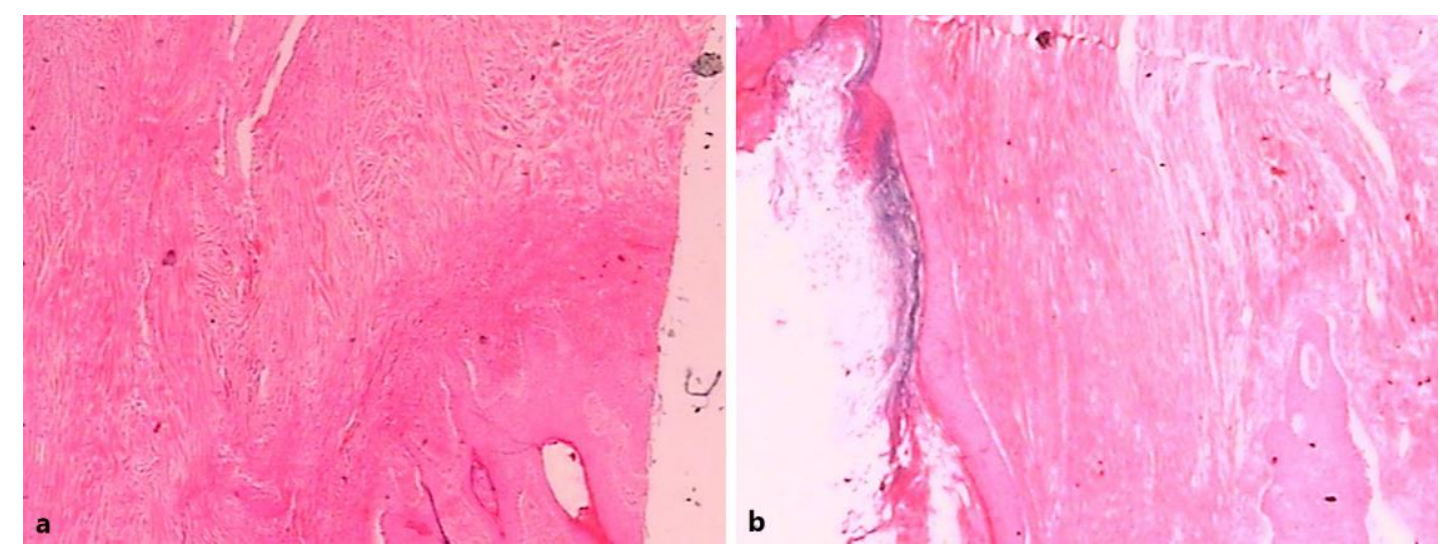

Fig. 3. Histopathological appearance of CSC. a Bundles of collagen were arranged in a storiform pattern mixed with fibroblasts. H\&E. $\times 20$. b Collagen bundles were separated by elongated clefts. $H \& E . \times 20$. 